\title{
Comparison of surface properties and physiological effects of a synthetic and a natural surfactant in preterm rabbits
}

\author{
J D Corcoran, P Berggren, B Sun, H L Halliday, B Robertson, T Curstedt
}

\begin{abstract}
Aims-To compare the physical and physiological properties of a synthetic surfactant (Exosurf, Wellcome Foundation) and a natural surfactant (Curosurf, Chiesi Farmaceutici).

Methods-Surface properties of the surfactant suspensions $(10 \mathrm{mg}$ phospholipid/ml) were evaluated using the pulsating bubble surfactometer. Lung-thorax compliance was determined in 47 immature newborn rabbits with a gestational age of 27 days, treated with recommended clinical doses of either surfactant (Exosurf 67.5 mg/kg; Curosurf $200 \mathrm{mg} / \mathrm{kg}$ ). The lungs were examined histologically. Results-The mean (SD) contractile forces of the surface at maximum and minimum bubble size were significantly lower for Curosurf than for Exosurf: 31 (2) and $0(0) \mathrm{mN} / \mathrm{m} v 53(5)$ and $29(4) \mathrm{mN} / \mathrm{m}$, respectively. Mean (SD) lung-thorax compliance after one hour of ventilation was significantly higher in rabbits treated with Curosurf compared with animals receiving Exosurf or those serving as controls: $0.60(0.15) \mathrm{ml} / \mathrm{cm} \mathrm{H}_{2} O . \mathrm{kg} v 0.44$ $(0.03)$ and $0.34(0.18) \mathrm{ml} / \mathrm{cm} \mathrm{H}_{2}$ O.kg, respectively. Both surfactants increased alveolar volume density compared with results for control animals, but only Curosurf significantly reduced the incidence of moderate or severe bronchiolar epithelial disruption.
\end{abstract}

Conclusions-The natural surfactant, Curosurf, reduced the contractile force at an air-liquid interface to a greater extent than the synthetic surfactant, Exosurf, and led to a greater improvement in compliance and less airway epithelial damage when given in clinical treatment doses to immature rabbits.

(Arch Dis Child 1994; 71: F165-F169)

Exosurf (Wellcome Foundation Ltd) and Curosurf (Chiesi Farmaceutici SpA) are two widely used surfactant preparations which have important differences in their constituents. Exosurf is a protein free synthetic surfactant consisting of dipalmitoyl phosphatidylcholine (DPPC) mixed with tyloxapol and cetyl alcohol; these increase the adsorption of DPPC at an air-liquid interface. ${ }^{1}$ Curosurf is a chloroform extract of polar lipids from pig lung which also contains $1 \%$ hydrophobic surfactant proteins - SP-B and SP-C. ${ }^{2}$ There is evidence to suggest that synthetic, protein free surfactants are less effective than natural (animal derived) surfactants containing proteins in increasing lung compliance in immature newborn rabbits ${ }^{34}$ and lambs. ${ }^{56}$ Nevertheless, overviews of clinical trials have shown that both types of surfactant reduce the odds of neonatal mortality associated with respiratory distress syndrome by about $40 \% .{ }^{7} \mathrm{We}$ compared the physical properties of these two surfactants in vitro, and lung-thorax compliance and alveolar volume density after administration of clinical treatment doses to immature newborn rabbits.

\section{Methods}

Curosurf was isolated from minced pig lungs by a sequence of washing, centrifugation, chloroform-methanol extraction and liquid gel chromatography. ${ }^{2}$ The phospholipid content of the suspension was $80 \mathrm{mg} / \mathrm{ml}$, the content of DPPC about $34 \mathrm{mg} / \mathrm{ml}$. Exosurf was supplied as a lyophilised powder which was suspended in water for injection at a concentration of $13.5 \mathrm{mg}$ phospholipid/ml.

Suspensions of Curosurf and Exosurf were diluted in normal saline to a concentration of $10 \mathrm{mg}$ phospholipid $/ \mathrm{ml}$. The surface properties of these suspensions were determined at $37^{\circ} \mathrm{C}$ using the pulsating bubble surfactometer (Surfactometer International, Toronto, Canada). ${ }^{8} \mathrm{~A}$ bubble communicating with the ambient air was created in each surfactant suspension and by varying the pressure applied to the suspension it was made to pulsate between a radius of $0.55 \mathrm{~mm}$ and $0.40 \mathrm{~mm}$ at a rate of 40 a minute. By measuring the pressure gradient (p) across the bubble wall the contractile force at the air-liquid interface $(\gamma)$ at minimum and maximum bubble size ( $\gamma$ min, $\gamma \max )$ was calculated according to the law of Laplace $(p=2 \gamma / r)$.

\section{ANIMAL EXPERIMENTS}

New Zealand white rabbit fetuses were delivered by hysterotomy at a gestational age of 27 days (term is 31 days) and immediately anaesthetised with an injection of $0.6 \mathrm{mg}$ intraperitoneal sodium pentobarbital, paralysed with $0.02 \mathrm{mg}$ intraperitoneal pancuronium bromide, and subjected to tracheotomy to permit endotracheal intubation with a metal cannula. Litter mates were randomly allocated to either one of two treatment groups Curosurf $200 \mathrm{mg} / \mathrm{kg} \quad(\mathrm{n}=15)$ or Exosurf $67.5 \mathrm{mg} \mathrm{DPPC} / \mathrm{kg}(\mathrm{n}=15)$ - or to an untreated control group $(n=17)$. The animals were then 
transferred to multiple body plethysmographs at a temperature of $37^{\circ} \mathrm{C}$ and connected in parallel to a pressure-constant ventilator (Servo-Ventilator 900B, Siemens-Elema). They were ventilated at a frequency of $40 /$ minute in $100 \%$ oxygen using an inspiration:expiration ratio of $1: 1$. Peak inspiration pressure was adjusted every five minutes to maintain a physiological tidal volume (about $10 \mathrm{ml} / \mathrm{kg}$ ) by altering the length of an open ended high resistance tube which was the outflow limb of the connection between the common ventilator tube and the tracheal cannula. ${ }^{9}$ This provides a reasonably square waveform with a peak pressure plateau of about 0.5 seconds at this ventilator rate. No positive end expiratory pressure (PEEP) was applied because this could have masked a difference in lung stabilising properties between the preparations. ${ }^{10} \mathrm{~A}$ four lead electrocardiogram (ECG) recording was obtained by inserting fine subcutaneous needles into the limbs. The animals were ventilated for 60 minutes and simultaneous recordings of ECG, tidal volume, and peak inspiratory pressure were obtained at 15 minute intervals on a multichannel recorder. Physiological data were accepted for analysis from animals with a regular heart rate $(>200 /$ minute $)$ and normal QRS complexes. Lung-thorax compliance was calculated from the tidal volume and peak inspiratory pressure. Following the period of ventilation, the animals were killed with an intracranial injection of $10 \mathrm{mg}$ lidocaine which causes immediate cardiac arrest. The abdomen was opened and the diaphragm inspected for evidence of pneumothorax. The chest was then opened and blood was aspirated from the right ventricle for measurement of $\mathrm{pCO}_{2}$ and $\mathrm{pH}$.

The lungs were expanded with a transpulmonary pressure of $30 \mathrm{~cm} \mathrm{H}_{2} \mathrm{O}$ for 30 seconds; the pressure was then lowered to $10 \mathrm{~cm} \mathrm{H}_{2} \mathrm{O}$ during fixation by vascular perfusion with a mixture of $4 \%$ formaldehyde and $1 \%$ glutaraldehyde. A deflation pressure of 10 $\mathrm{cm} \mathrm{H}_{2} \mathrm{O}$ represents a sensitive point of the pressure-volume diagram at which a substantial difference in volume is to be expected between a surfactant deficient lung and a lung treated with an effective surfactant. ${ }^{11}$ Large paraffin wax sections from the basal parts of both lungs were stained with haematoxylin and eosin and examined by conventional light microscopy.

Volume density of the alveolar spaces (Vv) was determined by conventional point counting, using 25 random fields for each lung and the total parenchyma as a reference volume. ${ }^{4}$

Table 1 General characteristics of experimental animals and physiological data after 60 minutes of ventilation

\begin{tabular}{lccc}
\hline & Exosurf & Curosurf & Control \\
\hline No of rabbits studied & 15 & 15 & 17 \\
Mean (SD) birth weight (g) & $29 \cdot 4(3 \cdot 1)$ & $30 \cdot 5(3 \cdot 0)$ & $31 \cdot 7(3 \cdot 3)$ \\
No surviving ventilation for one hour & 11 & 10 & 7 \\
Mean (SD) tidal volume (m/kg) & $10 \cdot 4(0 \cdot 6)$ & $10 \cdot 4(1 \cdot 0)$ & $10 \cdot 0(0 \cdot 6)$ \\
Mean (SD) peak inspiratory pressure $\left(\mathrm{cm} \mathrm{H}_{2} \mathrm{O}\right)$ & $23 \cdot 5(1 \cdot 3)$ & $18 \cdot 3(4 \cdot 6)^{\star}$ & $25 \cdot 0(3 \cdot 9)$ \\
Mean (SD) heart rate (beats/minute) & $304(33)$ & $293(26)$ & $279(51)$ \\
Mean (SD) pCO 2 (kPa) & $6 \cdot 1(2 \cdot 4)$ & $7 \cdot 3(2 \cdot 6)$ & $6 \cdot 8(2 \cdot 3)$ \\
\hline
\end{tabular}

Carbon dioxide tension $\left(\mathrm{pCO}_{2}\right)$ was determined in blood from right ventricle.

${ }^{\star} p<0.01$ compared with Exosurf and control animals.

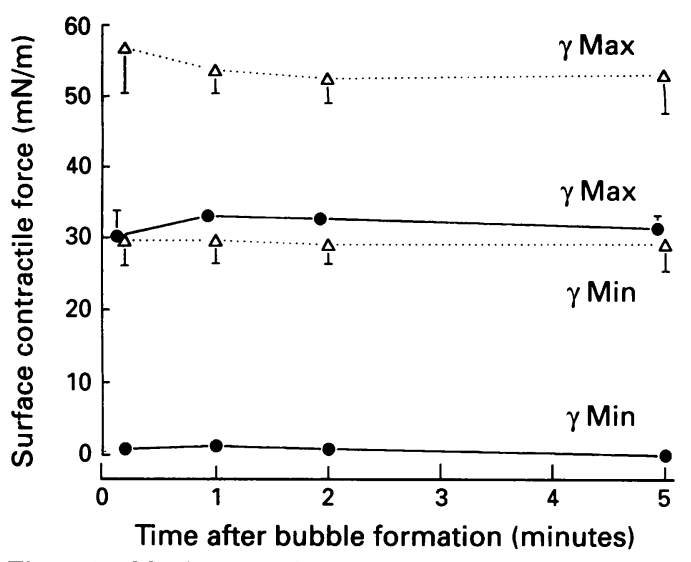

Figure 1 Maximum and minimum surface contractile force ( $\gamma$ max; $\gamma$ min; $m N / m$ ) of Curosurf (-) and Exosurf $(\triangle \ldots \triangle)$ (both $10 \mathrm{mg} / \mathrm{ml}$ ) calculated from measurements with the pulsating bubble surfactometer at $37^{\circ} \mathrm{C}$. Values are mean (SD) of five separate determinations. Overlapping SD bars are omitted for clarity, and bars falling within the symbols are not shown. $p<0 \cdot 01$ at all time points.

The degree of airway epithelial injury ${ }^{12}$ was examined by screening of the entire sections and expressed semi-quantitatively on a four degree scale: none; mild (isolated desquamated necrotic epithelial cells); moderate (small sheets of desquamated necrotic epithelium); severe (large sheets of desquamated necrotic epithelium).

All these assessments were made blind - that is, without knowledge of the experimental condition of individual animals.

\section{STATISTICS}

Values are given as mean (SD). Differences in surface properties were analysed using the Mann-Whitney $U$ test. Intergroup differences in data derived from animal experiments were examined using analysis of variance followed by the Student-Newman-Keuls test. Differences in lung injury scores were evaluated using the Kruskal-Wallis one way analysis of variance by ranks. A $p$ value of less than 0.05 was regarded as significant.

\section{Results}

\section{SURFACE PROPERTIES}

Figure 1 shows the $\gamma \min$ and $\gamma \max$ of Exosurf $(n=5)$ and Curosurf $(n=5)$ at a phospholipid concentration of $10 \mathrm{mg} / \mathrm{ml}$. Values for $\gamma \mathrm{min}$ recorded seven seconds to five minutes after onset of pulsation were about $30 \mathrm{mN} / \mathrm{m}$ for Exosurf and close to $0 \mathrm{mN} / \mathrm{m}$ for Curosurf. Values for $\gamma \max$ were above $50 \mathrm{mN} / \mathrm{m}$ in Exosurf samples and below $35 \mathrm{mN} / \mathrm{m}$ in samples of Curosurf. The differences between the two surfactants were significant for both measurements of surface contractile force at all time intervals $(p<0.01)$.

DATA FROM ANIMAL EXPERIMENTS

The three groups of animals are characterised in table 1. Eight control, two from the Exosurf group and three from the Curosurf group developed pneumothoraces. In two additional 


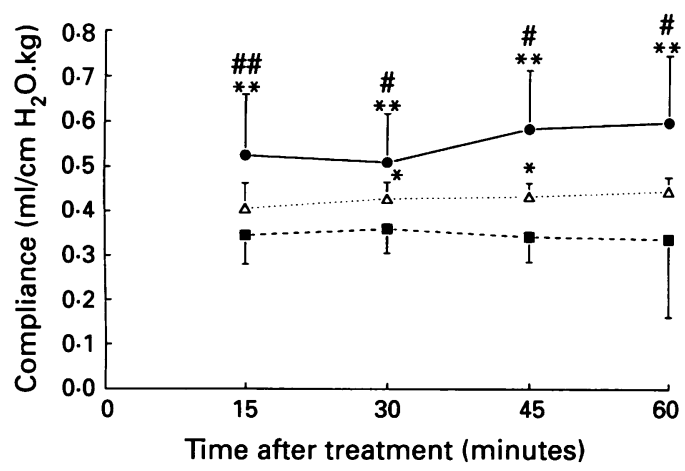

Figure 2 Lung-thorax compliance $\left(\mathrm{mL}_{\mathrm{cm} \mathrm{H}} \mathrm{O} . \mathrm{kg}\right)$ at 15 minute intervals after administration of Curosurf (and Exosurf $(\triangle \ldots \triangle)$ compared with controls ( - - Values are mean (SD); bars falling within the symbols are not shown. ${ }^{\star} p<0.05,{ }^{\star \star} p<0.01,{ }^{\star \star \star} p<0.001 \mathrm{v}$ controls, \# $<0.05$, \#p<0.01 v Exosurf.

animals in each group severe ECG abnormalities (arrhythmia or disappearance of QRS complexes) were recorded during the course of the experiment. Physiological data from these animals were accepted only from the period showing a normal ECG. A total of 28 animals survived the whole period of ventilation without complications. Tidal volumes, heart rate, and $\mathrm{pCO}_{2}$ in surviving animals were similar in all three groups (table 1 ).

Peak inspiratory pressure, required to maintain the standardised tidal volume, was significantly lower in animals treated with Curosurf than in those receiving Exosurf or those serving as controls (table 1). In other words, animals treated with Curosurf had higher lung-thorax compliance. This difference between the groups was significant throughout the experiment (fig 2). Final values for compliance, recorded after 60 minutes, were $0.60(0.15)$ $\mathrm{ml} / \mathrm{cm} \mathrm{H}_{2} \mathrm{O} . \mathrm{kg}$ in the Curosurf group, 0.44 $(0.03) \mathrm{ml} / \mathrm{cm} \mathrm{H}_{2} \mathrm{O} . \mathrm{kg}$ in animals receiving Exosurf, and $0.34(0.18) \mathrm{ml} / \mathrm{cm} \mathrm{H}_{2} \mathrm{O} . \mathrm{kg}$ in controls. Animals treated with Exosurf also had a significant improvement in compliance at 30 and 45 minutes compared with controls $(\mathrm{p}<0.05)$.

Morphometric data are summarised in table 2 and the incidence of various degrees of epithelial injury are shown in table 3 . As the numbers were very small in some subgroups, groups 1 and 2 with no or mild epithelial lesions, and groups 3 and 4 with moderate or severe lesions, were combined for analysis. Representative photomicrographs of the lung histology are shown in fig 3. Control animals had a low alveolar $\mathrm{Vv}$ with a large field to field variability in alveolar expansion, as reflected by a high coefficient of variation $\mathrm{CV}(\mathrm{Vv})$ (table 2). Most control rabbits developed moderate or severe airway epithelial damage (table 3) (fig 3A). In animals treated with Curosurf alveoli were more expanded with a $74 \%$ improvement

Table 2 Alveolar volume density ( $V v)$ and its coefficient of variation [CV(Vv)] in surviving immature rabbits

\begin{tabular}{llll}
\hline & Exosurf $(n=11)$ & Curosurf $(n=10)$ & Controls $(n=7)$ \\
\hline Mean (SD) Vv & $0.52(0 \cdot 07)^{\star}$ & $0.66(0.08)^{\star} \dagger$ & $0.38(0 \cdot 10)$ \\
Mean (SD) CV (Vv) & $0.17(0.07)^{\star}$ & $0.13(0.05)^{\star}$ & $0.26(0.05)$ \\
\hline
\end{tabular}

${ }^{\star} \mathrm{p}<0.01 v$ control rabbits. $\mathrm{tp}<0.01 v$ Exosurf.
Table 3 Bronchiolar epithelial injury in surviving animals

\begin{tabular}{llll}
\hline & $\begin{array}{l}\text { Exosurf } \\
(n=11)\end{array}$ & $\begin{array}{l}\text { Curosurf } \\
(n=10)\end{array}$ & $\begin{array}{l}\text { Controls } \\
(n=7)\end{array}$ \\
\hline None or mild & 4 & $9^{\star}$ & 2 \\
Moderate or severe & 7 & 1 & 5
\end{tabular}

${ }^{\star} \mathrm{p}<0.05$ for Curosurf rabbits with no or mild bronchiolar epithelial injury compared with moderate or severe injury $v$ Exithelial injury compared with

in $\mathrm{Vv}$ compared with the controls, and low $\mathrm{CV}$ (Vv) (table 2); airway epithelial injury was usually absent or mild (table 3) (fig 3C).

Treatment with Exosurf led to a $37 \%$ improvement of alveolar $\mathrm{Vv}$ associated with a reduction in $\mathrm{CV}(\mathrm{Vv})$ but did not significantly reduce the number of animals showing moderate to severe epithelial lesions (table 3) (fig 3B).

\section{Discussion}

The biophysical and physiological properties of a natural surfactant, Curosurf, and a synthetic, protein free preparation, Exosurf, show major differences. In the pulsating bubble at minimum bubble size the surface contractile force of Exosurf was much higher than that of Curosurf. These findings support the findings of a recent study by Hall et al ${ }^{13}$ which showed that the surface properties of Exosurf may be improved by the addition of surfactant proteins B and C, which are constituents of Curosurf and other naturally derived surfactants.

We are aware of the fact that calculation of the contractile force at the air-liquid interface becomes inexact when the pressure gradient approaches zero, because the bubble loses its spherical shape. However, the absolute error is less than $<0.5 \mathrm{mN} / \mathrm{m}$ which does not affect the validity of our results. ${ }^{14}$ With a pressure gradient of $0 \mathrm{~cm} \mathrm{H} \mathrm{H}_{2} \mathrm{O}$ the calculated contractile force will be $0 \mathrm{mN} / \mathrm{m}$, irrespective of the bubble radius. We therefore feel that values for contractile force close to zero (in our study observed only with the natural surfactant preparation) are indeed representative of the physical state of the bubble surface and probably indicate solidification of the interface due to selective squeeze-out of unsaturated film components. ${ }^{15}$

Immature rabbits treated with Curosurf had a greater improvement in lung compliance than those who received Exosurf. Previous studies in rabbits ${ }^{34}$ and lambs ${ }^{56}$ have shown similar benefits of natural surfactants. Apart from the effects of surfactant proteins another contributory factor may be the smaller dose of Exosurf $(67.5 \mathrm{mg} / \mathrm{kg} v 200 \mathrm{mg} / \mathrm{kg}$ of Curosurf, corresponding, however, to nearly the same dose of DPPC) and the larger volume of fluid instilled in the Exosurf group $(5 \mathrm{ml} / \mathrm{kg} v 2.5$ $\mathrm{ml} / \mathrm{kg}$ ). Previous studies have shown that babies receiving a higher dose of natural surfactant have better oxygenation than those receiving a lower dose. ${ }^{16-18}$ It could be argued that Exosurf was not given according to the manufacturer's instructions for clinical use in our study. However, slow infusion of surfactant via an endotracheal tube adaptor is not 

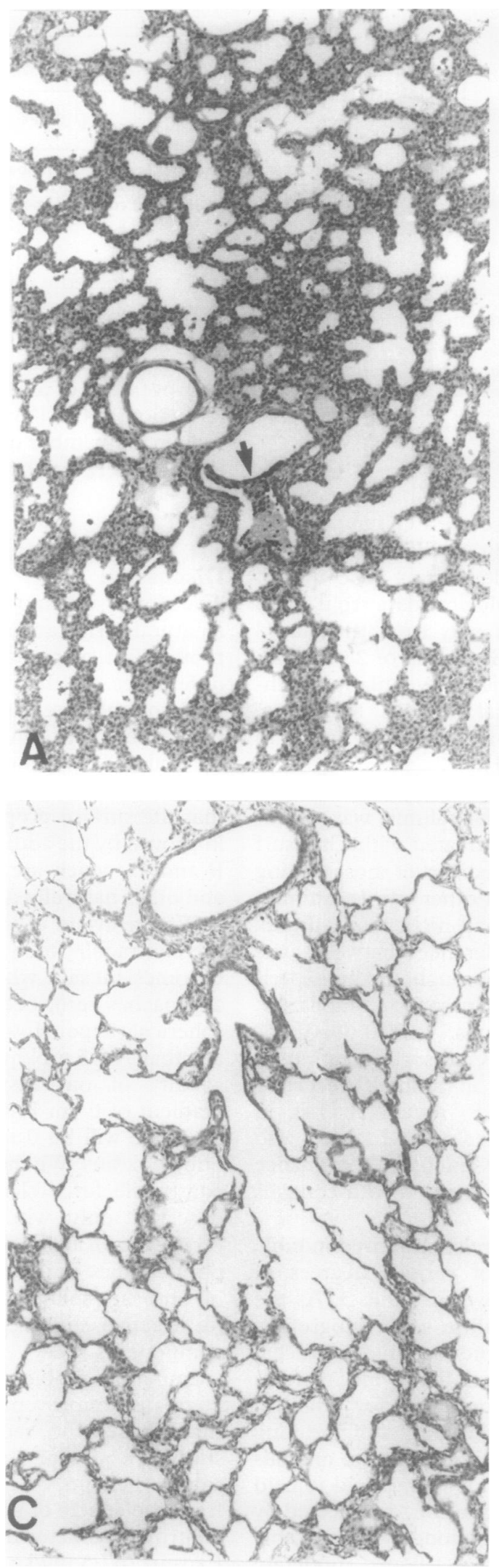

feasible in these small experimental animals. In one clinical trial Exosurf was given rapidly over five seconds through such an adaptor. ${ }^{19}$

The relative improvements in compliance, noted in the present series after treatment with Curosurf and Exosurf and ventilation for 60 minutes without PEEP $(+76 \%$ and $+29 \%$, respectively), were of the same order as those observed by Rider et al in preterm newborn rabbits after treatment with natural sheep

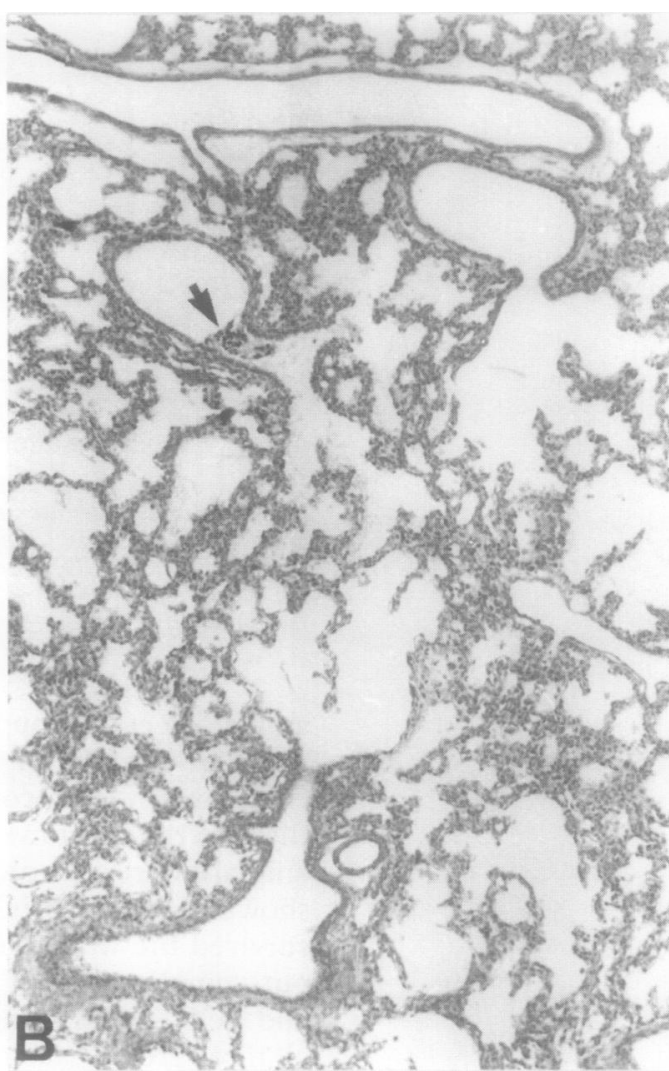

Figure 3 Histological sections of lung showing the effects of surfactant on expansion and airway epithelium (haematoxylin and eosin staining, X80). (A) Control animal with poor alveolar expansion and prominent disruption of the airway epithelium (arrow); (B) Exosurf treated animal with irregular alveolar expansion and moderate airway epithelial lesions (arrow); (C) Curosurf treated animal with mostly well expanded alveoli and no evidence of airway epithelial injury.

surfactant $(+77 \%)$ or Exosurf $(+14 \%) .{ }^{10}$ The improvement in the Curosurf group was slightly larger than the average $(+66 \%)$ reported in a previous study evaluating different batches of the same surfactant under nearly identical experimental conditions. ${ }^{9}$ Ventilation with PEEP leads to further improvement of compliance in preterm animals treated with Exosurf, Survanta, and natural sheep surfactant, ${ }^{10}$ indicating that comparison of different exogenous surfactants in ventilated newborn animals require rigorous standardisation of the experimental conditions.

In our study both surfactants effectively expanded the alveoli, as measured by volume density compared with controls, but Curosurf caused a significantly greater increase than Exosurf $(+74 \% v+37 \%)$ in keeping with the observed changes in compliance. More importantly, Curosurf was much more effective in preventing epithelial disruption. Epithelial lesions in the airways occur shortly after the start of mechanical ventilation in the surfactant deficient lung, ${ }^{12}$ and are associated with leakage of protein into the alveolar spaces $^{20}$ which may lead to further surfactant inactivation ${ }^{21}$ and increased protein leakage. There is evidence that the resultant activation of proteolytic enzymes increases the likelihood of bronchopulmonary dysplasia. ${ }^{22}$

Both Curosurf ${ }^{23}$ and Exosurf ${ }^{24} 25$ significantly reduce mortality when used in clinical 
rescue trials. However, the results of such trials are not directly comparable because of different patient populations, variable disease severity, and different contributing hospitals. The clinical importance of our observations can be tested only by direct comparative clinical trials of natural and synthetic surfactants to establish the most effective treatment of neonatal respiratory distress syndrome. Such trials need to be large enough to have a reasonable chance of detecting clinically important differences in outcomes ${ }^{26}$ such as death or the combination of death or bronchopulmonary dysplasia.

This work was supported by the Swedish Medical Research Council (Project No 3351), Oscar II:s Jubileumsfond, Axel Tielman's Minnesfond, and the General Maternity Hospital Foundation. Our thanks are due to Mrs Samantha Jameson for typing the manuscript.

1 Tooley WH, Clements JA, Muramatsu K, Brown CL Schlueter MA. Lung function in prematurely delivered rabbits treated with a synthetic surfactant. Am Rev Respir Dis 1987; 136: 651-6.

2 Robertson B, Curstedt T, Johansson J, Jörnvall H, Kobayashi T. Structural and functional characterisation of porcine surfactant isolated by liquid-gel chromatography. In: Von Wichert P, Müller B, eds. Basic research on lung surfactant. Progress in respiration research. Vol 25. Basel: Karger, 1989: 237-46.

3 Morley CJ, Robertson B, Lachmann B, Nilsson $R$ Bangham A, Grossmann G, et al. Artificial and natural
surfactant: Comparative study of the effect on premature surfactant: Comparative study of the effect on

4 Halliday HL, Nilsson R, Robertson B, Rigaut J-P, Grossmann G. Automated image analysis of the alveolar expansion pattern in immature rabbits treated with artificial or natural surfactant. Br f Exp Pathol 1987; 68: 727-32.

5 Egan EA, Notter RH, Kwong MS, Shapiro DL. Natural and artificial lung surfactant replacement therapy in premature lambs. $\mathcal{F}$ Appl Physiol 1983; 55: 875-83.

6 Cummings J, Holm BA, Hudak ML, Hudak BB, Ferguson WH, Egan EA. A controlled clinical comparison of four WH, Egan EA. A controlled clinical comparison of four
different surfactant preparations in surfactant-deficient different surfactant preparations in surfactant-deficient
preterm lambs. Am Rev Respir Dis 1992; 145: 999-1004.

preterm lambs. Am Rev Respir Dis 1992; 145: 999-1004.
7 Jobe AH. Pulmonary surfactant therapy. N Engl f Med 1993; 328: 861-7.

8 Enhorning G. Pulsating bubble technique for evaluating pulmonary surfactant. $\mathcal{F}$ Appl Physiol 1977; 43: 198-203

9 Sun B, Kobayashi T, Curstedt T, Grossmann G, Robertson B. Application of a new ventilator-multi-plethysmograph system for testing the efficacy of surfactant replacement in newborn rabbits. Eur Respir ₹ 1990; 4: 364-70.

10 Rider ED, Jobe AH, Ikegami M, Sun B. Different ventilation strategies alter surfactant responses in preterm rabtion strategies alter surfactant respons
bits. $\mathcal{F}$ Appl Physiol 1992; 73: 2089-96.

11 Fujiwara T. Surfactant replacement in neonatal RDS. In Robertson B, Van Golde LMG, Batenburg J, eds. Pulmonary surfactant. Amsterdam: Elsevier Science, 1984 479-503.
12 Nilsson R, Grossmann G, Robertson B. Lung surfactant and the pathogenesis of neonatal bronchiolar lesions induced by artificial ventilation. Pediatr Res 1978; 12: 249-55.

13 Hall SB, Venkitaraman AR, Whitsett JA, Holm BA, Notter $\mathrm{RH}$. Importance of hydrophobic apoproteins as constituents of clinical exogenous surfactants. Am Rev Respir stituents of clinical exo

14 Hall SB, Bermel MS, Ko YT, Palmer HT, Enhorning G, Notter RH. Approximations in the measurement of surface tension on the oscillatory bubble surfactometer. f Appl Physiol 1993; 75: 468-77.

15 Morley CJ, Bangham AD. Physical properties of surfactan under compression. In: Von Wichert P, ed. Progress in respiration research. Vol 15. Basel: Karger, 1981: 188-93.

16 Konishi M, Fujiwara T, Naito T, Takeuchi Y, Ogawa Y, Inukai $\mathrm{K}$, et al. Surfactant replacement therapy in neonatal respiratory distress syndrome. A multi-centre, natal respiratory distress syndrome. A multi-centre, dose of surfactant TA. Eur $¥$ Pediatr 1988; 147: 20-5.

17 Gortner L, Pohlandt F, Bartmann P, Bernsau U, Porz F, Hellwege $\mathrm{HH}$. High-dose versus low-dose bovine surfactant in very premature infants. Acta Paediatr 1994; 83: $135-41$

18 Halliday HL, Tarnow-Mordi WO, Corcoran JI, Patterson CC, on behalf of the European Multicentre Study Group. Multicentre randomised trial comparing high and low dose surfactant regimens for the treatment of respiratory distress syndrome (the Curosurf 4 trial). Arch Dis Child 1993; 69: 276-80.

19 Phibbs RH, Ballard RA, Clements JA, Heilbron DC Phibbs CS, Schlueter MA, et al. Initial clinical trial of Exosurf, a protein-free synthetic surfactant, for the proExosurf, a protein-free synthetic surfactant, for the pro-
phylaxis and early treatment of hyaline membrane disease phylaxis and early treatm

20 Robertson B, Berry D, Curstedt T, Grossmann G, Ikegam $M$, Jacobs $\mathrm{H}$, et al. Leakage of protein in the immature rabbit lung; effect of surfactant replacement. Respir Physiol 1985; 61: 265-76.

21 Kobayashi T, Nitta K, Ganzuka M, Inui S, Grossmann G, Robertson B. Inactivation of exogenous surfactant by pulmonary edema fluid. Pediatr Res 1991; 29: 353-6.

22 Merritt TA, Cochrane CG, Holcomb K, Bohl B, Hallman $\mathrm{M}$, Strayer $\mathrm{D}$, et al. Elastase and $\alpha$-proteinase inhibitor activity in tracheal aspirates during respiratory distress activity in tracheal aspirates during resp

23 Collaborative European Multicentre Study Group. Surfactant replacement therapy for severe neonatal respiratory distress syndrome: an international randomized clinical trial. Pediatrics 1988; 82: 683-91.

24 Long W, Corbet A, Cotton R, Courtney S, McGuiness G, Walter D, et al. The American Exosurf Neonatal Study Group I, and the Canadian Exosurf Neonatal Study Group. A controlled trial of synthetic surfactant in infants weighing $1250 \mathrm{~g}$ or more with respiratory distress syndrome. N Engl f Med 1991; 325: 1696-703.

25 Long W, Thompson T, Sundell H, Schumacher R, Volberg F, Guthrie R, and the American Exosurf Neonatal Study Group. Effects of two rescue doses of a synthetic surfactant on mortality rate and survival without bronchopulmonary dysplasia in 700- to 1360 -gram infants with monary dysplasia in $700-$ to 1360 -gram infants with
respiratory distress syndrome. $f$ Pediatr 1991; 118: respiratory

26 Horbar JD, Wright LL, Soll RF, Wright EC, Fanaroff AA, Korones SB, et al. A multicenter randomized trial comparing two surfactants for the treatment of neonatal respiratory distress syndrome. $\mathcal{f}$ Pediatr 1993; 123: 757-66. 